\title{
The relationship between nutritional status, anthropometric measurements and hemogram parameters in preobese and obese women before and after menopause
}

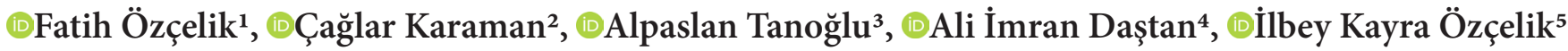 \\ ${ }^{1}$ University of Health Sciences Turkey, Sultan 2. Abdülhamid Han Training Hospital, Department of Medical Biochemistry, İstanbul, Turkey \\ ${ }^{2}$ University of Health Sciences Turkey, Hamidiye Faculty of Medicine, Department of Medical Biochemistry, İstanbul, Turkey \\ ${ }^{3}$ University of Health Sciences Turkey, Sancaktepe Şehit Prof. Dr. İlhan Varank Education and Research Hospital, Department of Internal \\ Medicine and Gastroenterology, İstanbul, Turkey \\ ${ }^{4}$ University of Health Sciences Turkey, Hamidiye Faculty of Medicine, Department of Medical Biochemistry, İstanbul, Turkey \\ ${ }^{5}$ Yeditepe University, Faculty of Medicine, İstanbul, Turkey
}

Cite this article as: Özcelik F, Karaman Ç, Tanoğlu A, Daştan Aİ, Özçelik İK. The relationship between nutritional status, anthropometric measurements and hemogram parameters in preobese and obese women before and after menopause. J Health Sci Med 2021; 4(4): 498-504.

\begin{abstract}
Objective: The nutritional status of pre-obese and obese women in the premenopausal and postmenopausal period is thought to be associated with anemia. In this study, we aimed to reveal the extent to which they meet their daily energy and nutrient needs and the relationship with the development of anemia by examining the food consumption records of women in the premenopausal and postmenopausal periods.

Material and Method: Women who applied to the Ataşehir District Health Directorate Healthy Nutrition and Active Life Unit for "Nutrition and Diet Consultancy" between May-July 2019 were included in the study. Women were divided into two groups as premenopause (36-45 years old) and postmenopause (46-73 years old) and their anthropometric measurements and nutritional status were evaluated. Serum glucose, blood urea nitrogen (BUN), creatinine, total-cholesterol, triglyceride, HDL, LDL, AST, ALT, iron, iron binding capacity, ferritin, vitamin B12, TSH, free T4, vitamin D and hemogram parameters of all participants were recorded.

Results: The waist circumference of $67.5 \%$ of the women in the premenopause group and $75 \%$ of the women in the postmenopausal group were above $88 \mathrm{~cm}$. The blood BUN and HDL levels of premenopausal women were found to be lower than those in the postmenopausal period (BUN: $10.6 \pm 3.51$ versus $15.06 \pm 4.96$ and HDL: $54.1 \pm 9.1$ versus 59, respectively. $3 \pm 13.5$; $\mathrm{p}<0.05$ ). Premenopausal women had lower blood ferritin levels and higher iron binding capacity (WBC) compared to postmenopausal women (Ferritin: $15.8 \pm 11.5$ versus $33.5 \pm 25.4$ and DBT: $311.12 \pm 61.7$ vs $287.50 \pm 41.93 ; \mathrm{p}<0.05)$. One of the important results of the study was the higher levels for vitamin D, AST and ALT in women in the post-menopausal period ( $\mathrm{p}<0.05)$.

Conclusion: It was determined that women in the premenopausal period did not receive enough iron and vitamin $\mathrm{D}$ to meet their needs. For this reason, daily food consumption should be adjusted accordingly, and lifestyle changes should be made to acquire healthy eating habits.
\end{abstract}

Keywords: Anemia, anthropometric measurements, nutrition, hemogram, menopause

\section{INTRODUCTION}

While deprivation and malnutrition are the main causes of disease and death in developing countries, eating disorders and obesity are more dominant problems in developed countries (1). Becoming overweight or pathological weight loss is inevitable when adequate and balanced nutrition cannot be achieved. Excessive weight gain is described as obesity, while excessive weight loss is defined as cachexia.
Body mass index (BMI), recommended by the World Health Organization, is still used in calculating obesity today. Different methods are also used for obesity classification, including waist circumference (WC) and central-peripheral fat mass. Recent data show that the incidence of obesity is rapidly increasing. This situation has made obesity a worldwide public health problem because excessive weight gain poses a high risk for many 
diseases, especially cardiovascular diseases, diabetes and cancers (2). Weight gain in the menopausal period is particularly striking. It was determined that women in the menopausal period gain approximately 0.7 kilograms per year, regardless of their racial-ethnic origin (3-5).

Menopause is characterized by low serum estradiol levels and high follicle stimulating hormone (FSH) levels due to complete or partial depletion of the follicles in the ovaries (6). Generally, between the ages of 45 and 55 , there is a transition period to menopause (pre-menopausal period lasting 3 to 8 years). Since there is no monthly blood loss after menopause, the need for iron is less than in the premenopausal period $(7,8)$.

In this study, the aim was to conduct a retrospective study to reveal iron deficiency anemia, which is thought to be related to nutritional status, by comparing the anthropometric measurements and blood parameters of pre-obese and obese women in the premenopausal and postmenopausal periods.

\section{MATERIAL AND METHOD}

The study is an analytical study and retrospective observational (case-control) study. For the research, permission was obtained from the Ethics Committee of the Health Sciences University Hamidiye Non-Interventional Ethics Committee (Date: 29.03.2019, Session No: 2019/3, Decision No: 19/33). This study was conducted with the approval (Date: 26/06/2019 6028, Decision No: 16867222604-01-01) of the Republic of Turkey Ministry of Health Research Platform. Permission was obtained from the Istanbul Provincial Health Directorate for the participants to be included in the study. All procedures were carried out in accordance with the ethical rules and the principles of the Declaration of Helsinki.

\section{Study Design}

A questionnaire was applied, and anthropometric measurements were performed for to voluntary preobese and obese women who applied to the Ataşehir District Health Directorate Healthy Nutrition and Active Life Unit for "Nutrition and Diet Consultancy". Women were grouped according to their age as premenopause and postmenopause. A total of 80 preobese or obese participants, with 40 people between the ages of 35-44 and a postmenopausal group of 40 people between the ages of 45-72 were included in the study. Those who had any acute or chronic disease that may cause iron deficiency anemia (hyperthyroidism, hypothyroidism, diabetes mellitus, infection, bleeding, hemorrhoids, cancer and hematological diseases, etc.), regular medication users (excluding vitamins and minerals), those who received iron replacement therapy in the last 6 months, those who had gynecological surgery, who had any metabolic disease, and any hormone replacement therapy (HRT) were excluded from the study.

\section{Research Plan}

First of all, the "Informed Consent Form" was read to the women participating in the study voluntarily and their consent was obtained. Survey questions were answered during face-to-face interviews. In the first part, there were questions determining the demographic characteristics of the participants. The second part included the "24-Hour Nutrition Form" including nutritional status evaluations of the individuals. Anthropometric measurements were height, body weight, waist circumference and body fat ratio measurements.

\section{Anthropometric Measurements}

Body weight and height were measured by using Tanita brand SC240MA model bioelectric impedance device with a sensitivity of 100 grams. In order to secure accurate measurements, all measurements were made in bare and dry feet after ensuring the of conditions such as three hours after getting out of bed, after going to the toilet, three hours after exercising, and approximately three hours after meals and excessive fluid intake. The same scale was used for all measurements.

Height was measured with feet side by side, head on the Frankfurt plane (eye triangle and auricle parallel to the ground) with a $0.01 \mathrm{~cm}$ sensitive height measuring device. Waist circumference was measured with a non-stretch tape measure. Again, the body fat ratio was automatically measured by the device during body weight measurements.

\section{Determination of Food Consumption Status}

Food consumption was determined by asking the participants face-to-face using the 24-hour reminder method. While recording food consumption, the volunteer participant was asked to indicate the amount of food consumed by hand and finger measurements and/or kitchen measurements.

Food consumption quantities were calculated according to references included in the located in Turkish Nutrition Guide "standard portion sizes and quantities of foods according to food group in Turkey" (9). In these definitions, food consumption was recorded by questioning the volunteer participants in detail using kitchen measurements (bowl, tablespoon, ladle, water glass, cup, dinner plate) and hand and finger measurements (fist and palm). Following the determination of the nutrient consumption amounts, volunteers' daily energy, water, fiber, polyunsaturated fat, cholesterol, macro (protein, fat, carbohydrate) and micro (A, E, B1, B2, B6 and C vitamins, carotene, folate, sodium, potassium, calcium, magnesium, phosphorus, zinc) nutrient consumption and the amount of iron they received from foods were calculated using the 
Nutrition Information Systems Package Program (BEBIS) version 7.2. Consumption amounts were compared with the recommended adequate intake in the Turkish Nutrition Guide (9). Energy and nutrient supply ratios of $66 \%$ were classified as under consumption and $\geq 133 \%$ as excess consumption (10).

\section{Biochemical Analysis}

After the blood samples were centrifuged, they were sent to the Public Health Laboratory by couriers and measurements were made under the supervision of laboratory experts with appropriate kits. Glucose, blood urea nitrogen (BUN), creatinine, total cholesterol, triglyceride, high-density lipoprotein (HDL), low-density lipoprotein (LDL), aspartate transaminase (AST), alanine transaminase (ALT), iron, total iron-binding capacity (TBIC), ferritin, vitamin B12, thyroid stimulating hormone (TSH), free T4, 25-hydroxy vitamin D and hemogram parameters were tested. Moreover, all participants in the study were asked to bring any biochemical analyses which were performed by the Family Medicine Unit in the last six months with them.

\section{Statistical Analysis}

Microsoft excel was used for all graphical representations and IBM Statistical Package for Social Sciences version 25 (SPSS) Chicago, IL, USA software was used for statistical analysis. Unpaired t test was used for parametric data in comparison of premenopause and postmenopausal groups and the Mann-Whitney $U$ test was used for the analysis of nonparametric data. Pearson correlation analyses were performed for the analysis of non-parametric data of all variables of the study, and Spearman correlation was used for the analysis of parametric data.

\section{RESULTS}

When Table 1 is examined, the difference between the ages in the premenopause and postmenopausal groups was statistically significant as expected $(\mathrm{p}<0.001)$. While the difference in favor of women in the premenopausal group in terms of mean height was statistically significant $(\mathrm{p}<0.05)$, there was no significant difference between mean weight $(p>0.05)$. The mean BMI of both groups were found to be statistically close to each other $(p>0.05)$.

Looking at Table 2, $12.5 \%$ of the participants in the premenopause group and $37.5 \%$ of the participants in the postmenopausal group had at least one chronic disease and the difference was statistically significant $(p<0.05)$. There was also a difference in terms of anemia status against women in the premenopausal group $(\mathrm{p}<0.05)$. Of those in the premenopause group with chronic diseases, $40 \%$ stated that they had asthma and $40 \%$ had coronary heart disease. In the postmenopausal group, $73.3 \%$ of those with chronic diseases stated that they had hypertension and $20 \%$ had asthma.

\begin{tabular}{|c|c|c|c|}
\hline & $\begin{array}{c}\text { Premenopausal } \\
\text { group }\end{array}$ & $\begin{array}{c}\text { Postmenopausal } \\
\text { group }\end{array}$ & P value \\
\hline $\mathrm{N}$ & 40 & 40 & - \\
\hline Age, year & $41.4 \pm 3.0$ & $54.7 \pm 6.6$ & $\mathrm{a}<0.0001$ \\
\hline Height, cm & $160.0 \pm 5.2$ & $156.2 \pm 5.5$ & $\mathrm{a}<0.0022$ \\
\hline Weight, kg & $81.28 \pm 17.13$ & $77,16 \pm 11.20$ & a0.2068 \\
\hline BMI, kg/m2 & $31.74 \pm 6.47$ & $31,74 \pm 5.19$ & a0.9970 \\
\hline $\begin{array}{l}\text { Waist } \\
\text { circumference, } \mathrm{cm}\end{array}$ & $95.20 \pm 13.23$ & $96.65 \pm 11.20$ & a0.5983 \\
\hline $\begin{array}{l}\text { Body fat } \\
\text { percentage, } \%\end{array}$ & $38.76 \pm 6.34$ & $39.36 \pm 4.88$ & a0.6394 \\
\hline
\end{tabular}

\begin{tabular}{|c|c|c|c|}
\hline & $\begin{array}{c}\text { Premenopausal } \\
\text { group }\end{array}$ & $\begin{array}{c}\text { Postmenopausal } \\
\text { group }\end{array}$ & P value \\
\hline $\mathrm{N}$ & 40 & 40 & - \\
\hline \multicolumn{4}{|c|}{ Anemia condition } \\
\hline $\begin{array}{l}\text { Yes, } \mathrm{n}(\%) \\
\text { No, n (\%) }\end{array}$ & $\begin{array}{l}12(\% 30) \\
28(\% 70)\end{array}$ & $\begin{array}{c}3(\% 7.5) \\
37(\% 92.5)\end{array}$ & b0.0442 \\
\hline \multicolumn{4}{|c|}{ Chronic disease status } \\
\hline $\begin{array}{l}\text { Yes, n (\%) } \\
\text { No, n (\%) }\end{array}$ & $\begin{array}{c}5(\% 12.5) \\
35(\% 87.5)\end{array}$ & $\begin{array}{l}15(\% 37.5) \\
25(\% 62.5)\end{array}$ & b0.0491 \\
\hline
\end{tabular}

BUN, HDL, AST and ALT levels of women in the premenopausal period were found to be lower than the postmenopausal group $(\mathrm{p}<0.05)$ (Table 3). Compared to the postmenopausal group, women in the premenopausal group had lower blood ferritin levels, whereas iron binding capacity values were higher $(\mathrm{p}<0.05)$. In addition, $25-\mathrm{OH}$ Vitamin D levels of women in the premenopausal group were lower than postmenopausal group $(\mathrm{p}<0.05)$. Hgb levels were lower in premenopausal women than in the postmenopausal group $(\mathrm{p}<0.05)$. However, it was found that HCT, MCV and RDW values did not accompany this decrease $(\mathrm{p}>0.05)$.

Macro and micronutrient consumption rates in the diets of women in the premenopause and postmenopausal groups are shown in Tables $\mathbf{4}$ and Table 5. There was no statistically significant difference between the women in the premenopausal and postmenopausal groups in terms of daily energy, water, protein, fat, carbohydrate, fiber, and polyunsaturated fat intake in their diets $(\mathrm{p}>0.05)$. This means that both groups are similar in terms of energy, water, protein, fat, carbohydrate, fiber, and polyunsaturated fat intake. However, daily cholesterol intake was found to be statistically higher in the premenopausal group compared to the postmenopausal group $(\mathrm{p}<0.05)$. 


\begin{tabular}{|c|c|c|c|}
\hline & $\begin{array}{l}\text { Premenopausal } \\
\text { group }\end{array}$ & $\begin{array}{l}\text { Postmenopausal } \\
\text { group }\end{array}$ & Pvalue \\
\hline $\mathrm{N}$ & 40 & 40 & \\
\hline Glucose, mg/dL & $91.2 \pm 8.4$ & $97.1 \pm 14.2$ & b0.0697 \\
\hline $\mathrm{BUN}, \mathrm{mg} / \mathrm{dL}$ & $10.6 \pm 3.51$ & $15.06 \pm 4.96$ & $a<0.0001$ \\
\hline Creatinine, mg/dL & $0.65 \pm 0.1$ & $0.68 \pm 0.09$ & $\mathrm{a} 0.2080$ \\
\hline Cholesterol, mg/dL & $212.7 \pm 33.8$ & $227.58 \pm 41.22$ & $\mathrm{a} 0.0826$ \\
\hline Triglyceride, $\mathrm{mg} / \mathrm{dL}$ & $123.8 \pm 61.1$ & $137.4 \pm 68.5$ & $\mathrm{a} 0.3498$ \\
\hline $\mathrm{HDL}, \mathrm{mg} / \mathrm{dL}$ & $54.1 \pm 9.1$ & $59.3 \pm 13.5$ & $\mathrm{a} 0.0492$ \\
\hline $\mathrm{LDL}, \mathrm{mg} / \mathrm{dL}$ & $133.3 \pm 29.4$ & $141.6 \pm 34.9$ & $\mathrm{a} 0.2540$ \\
\hline AST, IU/L & $18.3 \pm 4.8$ & $22.1 \pm 7.2$ & a0.0069 \\
\hline ALT, U/L & $16.9 \pm 7.3$ & $23.7 \pm 12.3$ & $\mathrm{a} 0.0034$ \\
\hline Iron, $\mu \mathrm{g} / \mathrm{dL}$ & $66.7 \pm 23.2$ & $70.43 \pm 21.30$ & $\mathrm{a} 0.4567$ \\
\hline TIBC, $\mu \mathrm{g} / \mathrm{dL}$ & $311.12 \pm 61.7$ & $287.50 \pm 41.93$ & $\mathrm{a} 0.0482$ \\
\hline Ferritin, ng/mL & $15.8 \pm 11.5$ & $33.5 \pm 25.4$ & $\mathrm{a} 0.0001$ \\
\hline $\begin{array}{l}\text { Vitamin } B_{12} \\
\text { pg/mL }\end{array}$ & $240.7 \pm 211.5$ & $261.4 \pm 143.3$ & $\mathrm{a} 0.6106$ \\
\hline $\begin{array}{l}25 \text {-hydroxy } \\
\text { vitamin } \mathrm{D}, \mathrm{ng} / \mathrm{mL}\end{array}$ & $16.91 \pm 6.14$ & $24.94 \pm 19.54$ & $\mathrm{a} 0.0152$ \\
\hline $\mathrm{Hgb}, \mathrm{g} / \mathrm{dL}$ & $12.41 \pm 1.03$ & $12.87 \pm 0.92$ & a0.0391 \\
\hline $\mathrm{WBC}, 10^{3} / \mu \mathrm{L}$ & $7.06 \pm 1.38$ & $6.28 \pm 1.09$ & $\mathrm{a} 0.006$ \\
\hline $\mathrm{RBC}, 10^{6} / \mu \mathrm{L}$ & $4.52 \pm 0.29$ & $4.60 \pm 0.35$ & $\mathrm{a} 0.2146$ \\
\hline HCT, \% & $37.89 \pm 2.85$ & $39.01 \pm 2.52$ & $\mathrm{a} 0.0654$ \\
\hline MCV-fL & $82.15 \pm 12.74$ & $84.96 \pm 4.78$ & $\mathrm{a} 0.1950$ \\
\hline RDW-\% & $13.97 \pm 1.05$ & $13.88 \pm 1.13$ & $\mathrm{a} 0.7120$ \\
\hline $\mathrm{PLT}, 10^{3} / \mu \mathrm{L}$ & $273.18 \pm 67.45$ & $246.03 \pm 51.57$ & $\mathrm{a} 0.0466$ \\
\hline
\end{tabular}

\begin{tabular}{|lccc|}
\hline \multicolumn{4}{|c|}{ Table 4. Macro nutrient and water consumption amounts of the } \\
participants in the premenopausal and postmenopausal groups \\
\hline & $\begin{array}{c}\text { Premenopausal } \\
\text { group }\end{array}$ & $\begin{array}{c}\text { Postmenopausal } \\
\text { group }\end{array}$ & $\begin{array}{c}\text { P } \\
\text { value }\end{array}$ \\
\hline N & 40 & 40 & \\
$\begin{array}{l}\text { Dietary energy, } \\
\text { kcal/day }\end{array}$ & $1650 \pm 392$ & $1500 \pm 309$ & $\mathrm{a} 0.055$ \\
$\begin{array}{l}\text { Water, mL/day } \\
\text { Dietary protein, } \\
\text { gr/day }\end{array}$ & $2839 \pm 792$ & $2625 \pm 1059$ & $\mathrm{a} 0.311$ \\
$\begin{array}{l}\text { Dietary fat, gr/day } \\
\text { Dietary carbohydrate, } \\
\text { gr/day }\end{array}$ & $18.4 \pm 19.7$ & $56.8 \pm 14.2$ & $\mathrm{~b} 0.444$ \\
$\begin{array}{l}\text { Dietary fiber, gr/day } \\
\text { Dietary cholesterol, } \\
\text { mg/day }\end{array}$ & $23.6 \pm 26.2$ & $62.8 \pm 19.1$ & $\mathrm{~b} 0.201$ \\
\hline $\begin{array}{l}\text { a Unpaired t test, b Mann-Whitney Test, } \\
\text { N: Number of the patients }\end{array}$ & $173.3 \pm 58.6$ & $\mathrm{~b} 0.064$ \\
\hline
\end{tabular}

\section{DISCUSSION}

Menopause is one of the important periods of a woman's life and is a natural process of normal aging $(11,12)$. Changes occur in blood biochemistry with hormonal changes due to menopause. As a reflection of this, eating habits can change, the tendency to obesity increases, and metabolic and physical changes can also be involved. Therefore, knowing what kind of changes might occur in women in this period will enable them to take precautions in advance and acquire nutritional habits according to the needs.
Table 5. Micronutrient consumption amounts of the participants in the premenopausal and postmenopausal groups

\begin{tabular}{|c|c|c|c|}
\hline & $\begin{array}{c}\text { Premenopausal } \\
\text { group }\end{array}$ & $\begin{array}{c}\text { Postmenopausal } \\
\text { group }\end{array}$ & P value \\
\hline $\mathrm{N}$ & 40 & 40 & \\
\hline $\begin{array}{l}\text { Dietary vitamin A, } \\
\mu \mathrm{g} / \text { day }\end{array}$ & $1153 \pm 741$ & $1380 \pm 1859$ & b0.3552 \\
\hline $\begin{array}{l}\text { Dietary carotene, } \\
\text { mg/day }\end{array}$ & $4.42 \pm 3.98$ & $4.67 \pm 4.75$ & b0.5037 \\
\hline $\begin{array}{l}\text { Dietary vitamin } \mathrm{E}, \\
\text { mg/day }\end{array}$ & $15.6 \pm 8.16$ & $14.2 \pm 8.17$ & b0.4945 \\
\hline $\begin{array}{l}\text { Dietary vitamin B1, } \\
\text { mg/day }\end{array}$ & $0.93 \pm 0.29$ & $0.88 \pm 0.25$ & b0,3865 \\
\hline $\begin{array}{l}\text { Dietary vitamin B2, } \\
\text { mg/day }\end{array}$ & $1.45 \pm 1.06$ & $1.16 \pm 0.43$ & b0.1503 \\
\hline $\begin{array}{l}\text { Dietary vitamin B6, } \\
\text { mg/day }\end{array}$ & $1.25 \pm 0.51$ & $1.17 \pm 0.38$ & b0.6580 \\
\hline $\begin{array}{l}\text { Dietary folate, } \\
\mu \mathrm{g} / \text { day }\end{array}$ & $339.7 \pm 172.1$ & $308.6 \pm 130.1$ & b0,2877 \\
\hline $\begin{array}{l}\text { Dietary vitamin } \mathrm{C} \text {, } \\
\mathrm{mg} / \text { day }\end{array}$ & $142.9 \pm 99.5$ & $149.5 \pm 106.3$ & b0.7111 \\
\hline $\begin{array}{l}\text { Dietary sodium, } \\
\text { mg/day }\end{array}$ & $3497 \pm 1296$ & $3395 \pm 1075$ & b0.9962 \\
\hline $\begin{array}{l}\text { Dietary potassium, } \\
\text { mg/day }\end{array}$ & $2651 \pm 821.6$ & $2519 \pm 839$ & b0.3288 \\
\hline $\begin{array}{l}\text { Dietary calcium, } \\
\text { mg/day }\end{array}$ & $798.9 \pm 248.0$ & $775.2 \pm 233.7$ & b0.5605 \\
\hline $\begin{array}{l}\text { Dietary magnesium, } \\
\text { mg/day }\end{array}$ & $302.5 \pm 100.8$ & $284.3 \pm 90.7$ & b0.2834 \\
\hline $\begin{array}{l}\text { Dietary phosphorus, } \\
\text { mg/day }\end{array}$ & $1051 \pm 310.9$ & $983.9 \pm 253.5$ & b0.4162 \\
\hline $\begin{array}{l}\text { Dietary iron, } \\
\text { mg/day }\end{array}$ & $11.26 \pm 4.75$ & $9.66 \pm 3.08$ & b0.1410 \\
\hline $\begin{array}{l}\text { Dietary zinc, } \\
\text { mg/day }\end{array}$ & $9.96 \pm 3.54$ & $8.49 \pm 2.33$ & b0.0767 \\
\hline
\end{tabular}

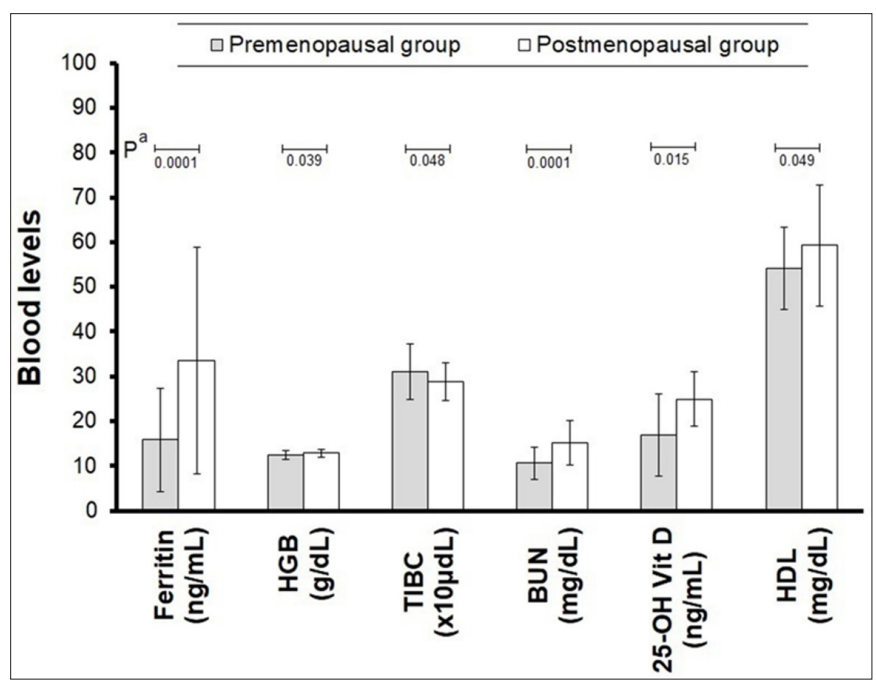

Figure. Ferritin, HGB, TIBC, BUN, 25-OH Vit D and HDL levels of premenopausal and postmenopausal women. The differences between the two groups in terms of parameters are seen clearly in the figure.

The premenopausal women who participated in our study were taller and this finding was parallel to the national data. Furthermore, these findings are consistent with data indicating that Turkey has increased the average height as an indicator of better nutrition in the younger population (13). 
When the groups are examined in terms of anemia status in our study, this situation was higher in premenopausal women. The most likely reason for this difference is iron deficiency anemia due to menstrual bleeding in the premenopausal period (14). Nutritional anemia may be associated with prolonged inadequate intake of folate, vitamin B12, iron, protein and vitamin C. Although it was reported that older women after menopause may be at high risk in terms of insufficient micronutrient intake (15), this study shows that losses due to the menstrual cycle are more prominent in women. In addition, the lower levels of ferritin, TIBC and Hgb in premenopausal women also supports our view.

In a study conducted by Schwarz et al. (16) the proportion of premenopausal women with one or more chronic diseases was $29.2 \%$ while this rate for postmenopausal women was $13.1 \%$. These rates were found to be $16.6 \%$ and $24.2 \%$ in premenopausal and postmenopausal women with three or more chronic diseases, respectively. These findings are similar to the results of our study in terms of the presence of more than one chronic disease. The probable reason for this finding is that postmenopausal women have a higher risk of developing chronic diseases due to the adverse metabolic consequences of both aging and menopause (17).

Although BUN is often used as an indicator of renal function and/or hydration status, it is also known to be an independent predictor of mortality in a large number of clinical settings and patient populations (18). In our study, unlike creatinine levels, postmenopausal women had higher BUN levels compared to the premenopausal group. This finding is thought to arise due to aging. That is, the total number of nephrons in a normal person gradually decreases with aging and diseases. Due to these losses, blood creatinine and BUN levels can be higher in the postmenopausal period (19). In our study, since creatinine levels were similar in both groups, the BUN levels of women in the postmenopausal group were attributed to the use of antihypertensive diuretic drugs rather than nephron loss. The presence of a history of hypertension in a significant portion of women in the postmenopausal group supports this conclusion because like creatinine, urea freely filters through the kidney glomeruli. However, compared to creatinine, urea can undergo substantial tubular reabsorption. This tubular reabsorption of urea may increase due to neurohormonal activation through direct effects on the distal nephron or indirect effects of water reabsorption due to reduced renal blood flow $(20,21)$. Neurohormonal activation induced by some anti-diuretics, such as loop diuretics, will also reduce BUN clearance. This explains why serum BUN levels may be higher in people using diuretics.
Today, HDL is known to increase due to physical activity. Therefore, HDL levels are expected to be low in postmenopausal women, where we expect less physical activity. On the contrary, the fact that HDL levels of postmenopausal women were significantly higher in our study was attributed to the antihyperlipidemic drugs used by postmenopausal women to relieve cardiovascular complications. Moreover, the finding that postmenopausal women are highly hypertensive confirms our claim. Studies reporting that physical activity and HDL levels decrease with aging (22) and the lack of difference in lipid profile in both groups other than HDL also support our claim. In addition, it is reported that estrogen is very effective on blood lipids and decreases LDL while increasing HDL. After menopause, the protective effect of estrogen disappears and causes an increase in LDL and triglyceride levels and this situation negatively affects HDL levels. Moreover, the deterioration of HDL/LDL ratio is an important risk factor for cardiovascular diseases. All this information is evidence that postmenopausal women in our study may have used antihyperlipidemic drugs to reduce their cardiovascular risk. Factors in the development of postmenopausal cardiovascular diseases include not only the estrogen hormone, but also dietary habits of premenopausal women, obesity, and smoking $(23,24)$.

The correlation between the development of menopause and impaired lipid metabolism leads to the emergence of obesity-related disorders, including metabolic syndrome. Therefore, in order to protect cellular structures from oxidative stress caused by estrogen deficiency, it is important for women who have entered menopause to eat adequate and balanced nutrition from antioxidative foods (25). In a recent cross-sectional study, postmenopausal women diagnosed with metabolic syndrome had higher plasma HDL cholesterol levels. On the other hand, the proportion of women with low HDL levels was higher in the premenopausal group. Therefore, it is thought that low HDL level may be the main characteristic finding of metabolic syndrome in postmenopausal women (26). In addition, in a study examining the lipid profile of healthy premenopausal and postmenopausal women (27), postmenopausal women had higher levels of total cholesterol, triglyceride, LDL and HDL.

According to data from the Turkish Nutrition and Health Survey (TNHS), mean AST level in women aged 31-50 years was 18.3 IU/L and mean ALT level was 17.5 IU/L. Mean AST level in the 51-64 age group was 21.5 IU/L and mean ALT level was 22,2 IU/L (28). In our study, AST values of the participants in the premenopausal group were lower than those in the postmenopausal group, but were similar to the results of the above study. We attributed the probable reason for the lack of difference 
between the groups as being due to the liver function tests of women changing significantly during the transition to menopause. This idea is confirmed by a recent study in which an increase in AST and ALT levels associated with triglyceride was found in postmenopausal women (29). As it is known, sedentary lifestyle and decreased physical activity with aging is characterized by fattening. This fattening is also observed in internal organs such as the liver. Fatty liver usually manifests itself with ALT elevation, and in some cases, elevated AST accompanies this (30).

According to TNHS data 28 in women between the ages of 31-50, mean serum iron level was $71.7 \mu \mathrm{g} / \mathrm{dL}$, serum TIBC was $332.19 \mu \mathrm{g} / \mathrm{dL}$, mean serum ferritin level was $26.6 \mathrm{ng} / \mathrm{mL}$, blood mean hemoglobin level was $12.7 \mathrm{~g} /$ $\mathrm{dL}$ and hematocrit value was $38.9 \%$. These values were $76.0 \mu \mathrm{g} / \mathrm{dL}, 315.7 \mu \mathrm{g} / \mathrm{dL}, 55.9 \mathrm{ng} / \mathrm{mL}, 13.2 \mathrm{~g} / \mathrm{dL}$ and $40.3 \%$, respectively, in women between the ages of 51 64. Compared to these results, our ferritin levels were found to be lower in premenopausal women. We think that this finding occurs due to menstrual bleeding in premenopausal women. Moreover, serum iron levels were heavily affected by daily dietary changes. Studies reported that people with iron deficiency develop anemia only in advanced stages and that it can be reflected in hemoglobin and hematocrit levels due to the depletion of ferritin stores (31). In addition, TIBC was found to accompany this tableau in inverse proportion to serum ferritin levels (31). On the other hand, as iron loss will disappear with the end of menstrual bleeding in the postmenopausal period, body iron stores will be filled, and ferritin level will be higher $(32,33)$.

According to the TNSH data, the vitamin D levels of women between the ages of 28, 31-50 and 51-64 years are $15.9 \mathrm{ng} / \mathrm{mL}$ and $17.3 \mathrm{ng} / \mathrm{mL}$, respectively. These values were similar to the findings in our study. However, it was higher in postmenopausal women who could benefit less from daylight because they were not in an active life period. However, some researchers (34), contrary to our results, found higher serum vitamin D levels in women in the premenopausal period. They found that vitamin D levels were lower especially in those who had dark skin, were overweight and elderly (35). Therefore, they recommended special diets and vitamin supplements to increase low serum vitamin D levels. The main reason why we found a different result from these researchers may be dietary. In addition, vitamin D level is determined by measuring $25-\mathrm{OH}$ vitamin $\mathrm{D}$, which is a prohormone. Because 25-OH vitamin D is the most stable and abundant form of vitamin $\mathrm{D}$ in serum due to its half-life of 3 weeks, using this metabolite is the most reliable method in measurements. For the diagnosis of vitamin $\mathrm{D}$ insufficiency, $30 \mathrm{ng} / \mathrm{ml}$ value is used as the cut-off value of serum 25-OH vitamin D level (36). In another study, it was revealed that the serum $25-\mathrm{OH}$ vitamin $\mathrm{D}$ level should be below $20 \mathrm{ng} / \mathrm{mL}$ in order to meet vitamin D deficiency (37). Vitamin D deficiency is a common finding accompanying obesity, increasing age, and unhealthy lifestyle. There are studies that show that adequate vitamin $\mathrm{D}$ level can be beneficial for bone, cardiovascular and general health, especially in women in the postmenopausal group (38). In light of the above information and our results, premenopausal women should take supplements for vitamin D.

It was reported that leukocytes decrease due to aging of bone marrow and decreases in its activity (39). Similarly, in our study, the WBC value of postmenopausal women was found to be lower compared to women in the premenopausal group. On the other hand, no difference was found between the daily zinc intake of women in the premenopause and postmenopausal groups. However, all women should be supported in dietary terms for iron and zinc (40).

\section{CONCLUSION}

Obese women in premenopause and postmenopausal periods should obtain adequate and balanced nutrition in accordance with their ages and conditions and their physical activity levels should be increased in order to increase their quality of life and protect their health. It should also be considered that the premenopausal group of obese women should take supplements in terms of vitamin $\mathrm{D}$ and iron.

\section{ETHICAL DECLARATIONS}

Ethics Committee Approval: Approval for the study was granted by the Ethics Committee of the University of Health Sciences Turkey, Hamidiye Scientific Research (Date: 29.03.2019, Session No: 2019/3, Decision No: 19/33). This study was conducted with the approval (Date: 26/06/2019 6028, Decision No: 16867222-60401-01) of the Republic of Turkey Ministry of Health Research Platform.

Informed Consent: "Informed Volunteer Consent" was obtained from the women participating in the study.

Conflict of Interest Statement: The authors have no conflicts of interest to declare.

Financial Disclosure: The authors declared that this study has received no financial support.

Author Contributions: All of the authors declare that they have all participated in the design, execution, and analysis of the paper, and that they have approved the final version. 


\section{REFERENCES}

1. Group TECW. Nutrition and reproduction in women. Hum Reprod Update 2006 ; 12: 193-207.

2. Tanoglu A, Kara M. Nonalcoholic fatty liver disease-related cardiovascular risk: Is there an association with blood hemoglobin levels? Eur J Gastroenterol Hepatol 2015; 27: 1126-9.

3. Davis SR, Castelo-Branco C, Chedraui P, Lumsden MA, Nappi $\mathrm{RE}$, Shah D, et al. Understanding weight gain at menopause. Climacteric 2012; 15: 419-29.

4. Sternfeld B, Wang H, Quesenberry CP, et al. Physical activity and changes in weight and waist circumference in midlife women: Findings from the study of women's health the nation. Am J Epidemiol 2004; 160: 912-22.

5. Karvonen-Gutierrez C, Kim C. Association of mid-life changes in body size, body composition and obesity status with the menopausal transition. Healthcare 2016; 4: 42.

6. Bacon JL. The Menopausal transition. Obstet Gynecol Clin North Am 2017; 44: 285-96.

7. Bayen S, Le Grand C, Bayen M, Richard F, Messaadi N. Anemia management in non-menopausal women in a primary care setting: a prospective evaluation of clinical practice. BMC Fam Pract 2020; 21: 13.

8. Alam F, Memon AS, Fatima SS. Increased body mass index may lead to hyperferritinemia irrespective of body iron stores. Pakistan J Med Sci 2015; 31: 1521-6.

9. Pekcan G, Şanlıer N, Baş M, editors. Turkey Dietary Guidelines. Ministery of Turkey Health Publication No: 1046; 2016.

10. Manore MM, Meacham SL. New dietary reference intakes set for energy, carbohydrates, fiber, fat, fatty acids, cholesterol, proteins, and amino acidss. ACSMs Health Fit J 2003; 7: 25-7.

11. Edwards BJ, Li J. Endocrinology of menopause. Periodontol 2000 2013; 61: 177-94.

12. Department of Obstetrics \& Gynecology U of CS of M. HHS Public Access. Menopausal symptoms and their management. Endocrinol Metab Clin North Am 2015; 44: 497.

13. Topçu S, Şimşek Orhon F, Ulukol B, Başkan S. Secular trends in height, weight and body mass index of primary school children in Turkey between 1993 and 2016. J Pediatr Endocrinol Metab 2017; 30: $1177-86$.

14. Saydam BK, Genc RE, Sarac F, Turfan EC. Prevalence of anemia and related factors among women in Turkey. Pakistan J Med Sci 2017; 33: 433-8.

15. Fishman SM, Christian P, West KP. The role of vitamins in the prevention and control of anaemia. Public Health Nutr 2000; 3: 125-50.

16.Schwarz S, Völzke H, Alte D, et al. Menopause and determinants of quality of life in women at midlife and beyond: the study of health in pomerania (SHIP). Menopause 2007; 14: 123-34.

17. World Health Organization. Preventing chronic diseases: a vital investment: WHO global report. Geneva (CH); 2005.

18. Sullivan DH, Sullivan SC, Bopp MM, Roberson PK, Lensing SY. BUN as an Independent Predictor of Post-Hospital-Discharge Mortality among Older Veterans. J Nutr Heal Aging 2018; 22: 759-65.

19. Wernly B, Lichtenauer M, Vellinga NAR, et al. Blood urea nitrogen (BUN) independently predicts mortality in critically ill patients admitted to ICU: A multicenter study. Clin Hemorheol Microcirc 2018; 69: 123-31.

20.Bakris GL, Ritz E. The message for World Kidney Day 2009: hypertension and kidney disease: a marriage that should be prevented. Vol. 75, Kidney international. United States; 2009. p. 449-52.

21. Testani JM, Cappola TP, Brensinger CM, Shannon RP, Kimmel SE. Interaction Between Loop Diuretic-Associated Mortality and Blood Urea Nitrogen Concentration in Chronic Heart Failure. J Am Coll Cardiol 2011; 58: 375-82.
22.Zwald ML, Akinbami LJ, Fakhouri THI, Fryar CD. Prevalence of low high-density lipoprotein cholesterol among adults, by physical activity: United States, 2011-2014. NCHS Data Brief 2017; 276: 1-8.

23. de Almeida Ventura D, de Matos Fonseca V, Ramos EG, et al. Association between quality of the diet and cardiometabolic risk factors in postmenopausal women. Nutr J 2014; 13: 121.

24. Jull J, Stacey D, Beach S, et al. Lifestyle Interventions Targeting Body Weight Changes during the Menopause Transition: A Systematic Review. J Obes 2014; 2014: 1-16.

25. Ko SH, Kim HS. Menopause-associated lipid metabolic disorders and foods beneficial for postmenopausal women. Nutrients 2020; 12 .

26. El Khoudary SR. HDL and the menopause. Curr Opin Lipidol 2017; 28: 328-36.

27. Ambikairajah A, Walsh E, Cherbuin N. Lipid profile differences during menopause: A review with meta-analysis. Menopause 2019; 26: 1327-33.

28. Turkey's health ministry. Turkey Nutrition and Health Survey 2019 (Türkiye beslenme ve sağlık araştırması (TBSA)). Ministry of Turkey Health Publication No: 1132; 2019.

29. Matsui S, Yasui T, Kasai K, et al. Changes of liver enzymes and triglyceride during the menopausal transition in Japanese women. J Obstet Gynaecol (Lahore) 2016; 36: 806-11.

30. Rinella ME. Nonalcoholic fatty liver disease: a systematic review. JAMA 2015 ; 313: 2263-73.

31. Gibson RS. Principles of nutritional assessment. Oxford university press, USA; 2005.

32. Jian J, Pelle E, Huang X. Iron and menopause: does increased iron affect the health of postmenopausal women? Antioxid Redox Signal 2009; 11: 2939-43.

33. Lerche CM, Philipsen PA, Wulf HC. UVR: sun, lamps, pigmentation and vitamin D. Photochem Photobiol Sci Off J Eur Photochem Assoc Eur Soc Photobiol 2017; 16: 291-301.

34. Fidan F, Alkan BM, Tosun A. Pandemic era: vitamin D deficiency and insufficiency. Turk J Osteoporos 2014; 20: 71-4.

35. Smith EM, Tangpricha V. Vitamin D and anemia. Curr Opin Endocrinol Diabetes Obes 2015; 22: 432-8.

36. Hansen KE, Johnson MG. An update on vitamin D for clinicians. Curr Opin Endocrinol Diabetes Obes 2016; 23: 440-4.

37.Lerchbaum E. Vitamin D and menopause - A narrative review. Maturitas 2014; 79: 3-7.

38. Kurosawa S, Iwama A. Aging and leukemic evolution of hematopoietic stem cells under various stress conditions. Inflamm Regen 2020; 40: 29.

39. Milman N, Kirchhoff M. Iron stores in 1359, 30- to 60-year-old Danish women: Evaluation by serum ferritin and hemoglobin. Ann Hematol 1992; 64: 22-7.

40. Mansour D, Hofmann A, Gemzell-Danielsson K. A review of clinical guidelines on the management of iron deficiency and iron-deficiency anemia in women with heavy menstrual bleeding. Adv Ther 2020; 1-25. 